\title{
Economics, Vulnerability \\ and the Diminishing Returns of Technology
}

\author{
by Orio Giarini *
}

\section{The concept of economlc growth : An introduction}

From ancient times up to the first industrial revolution, economic development was assumed to be as purely cyclical : at the end of a cycle, the situation was roughly the same as it was at the starting point. The economic theory implicit in the Bible is contained in the description of the seven fat years followed by the seven lean years. If any underlying growth trend existed, it was of such a long-term nature as to be imperceptible. This was natural in agricultural economies where relative wealth was very much a matter of territorial conquest. However, the majority of contemporary economists considering growth since the beginning of the industrial revolution have tended to assume that economic cycles in the developed countries are only a kind of variation (of a short or long-term nature) in an underlying trend of continuous growth.

This fundamental tendency has become more pronounced during the thirty years since the second world war to the extent that growth and more particularly the growth rate have assumed an importance unique in the history of mankind.

It is also assumed that this economic growth, based on material growth, is identical with the growth of material economic welfare.

\section{The growth factors}

Economic growth of course is not a purely economic phenomenon. It is the result of a combination of factors : demographic, financial, cultural, political, historical, technological, geographical, medical, etc. This very heterogeneous combinations is decisive, if it happens in the right way, at the right place and at the right time. The economic analysis of Simon Kuznets gives a good idea of these key factors, in particular capital and demography, not forgetting the more general framework.

Our purpose here is to try to answer such questions as: what has really made growth, as we have known it in the past decades, a unique historical performance? Can we try to improve the understanding of the mechanism in order to control it better, or just to understand better where we are going ?

It is an obvious and generally accepted hypothesis that technology has played a major role in providing the technical bases for growth. But the origin of technology, its characteristics and the mechanisms of its diffusion throughout the economic structure

\footnotetext{
* Lecturer at the Graduate Institute of European Studies, University of Geneva.
} 
are still unadequately analysed, for want of clearly defined communication between economists, technologists and natural scientists. And if the technological machinery is a fundamental factor which explains modern economic growth, present discussions on the limits of growth have to consider in a deeper way the question whether technology has limits or cycles, and if so, their type and nature. It is unsatisfactory to "believe" in technological innovation, and it is interesting to examine whether technology is also subject to the law of diminishing returns.

\section{The production function and the law of diminishing returns}

Every student of economics, at the very beginning of his course, becomes acquainted with the production function and the law of diminishing returns.

The production function is the equation showing which are the principal economic factors of production and how they are combined. In the early stages of classical economics, the factors taken into account were Land, Capital and Labour. Later on, the function was reduced to Capital and Labour only: theory had taken into account the diminishing importance of the land factor for industrial production and linked it with Capital. There has always been a clear and close relationship between a specific historical situation and the trends in economic theory. For instance, between 1873 and 1896 , in a period of drastic deflation, when capital was available at a very low rate of interest, and seemed almost to be free, some economists started to develop a production function which tended to exclude Capital. Conversely, in recent times, some other economists have centered the production function on the concept of Capital.

The law of diminishing returns states simply that given a fixed amount of one production factor, additional units of the other production factors bring diminishing yields until the point is reached at which the last, marginal unit of the factor will yield nothing. The classical case involves a fixed amount of land where adding units of labour (and/or capital) will increase the total yield but in a decreasing amount for each additional unit, until no increase at all becomes possible. This theory is one of the very fundamental laws from which many theoretical developments derive : the law of competition in a free market enterprise system and its capacity to optimize production in conjunction with the free supply and demand mechanism, as well as the marxist theory and the malthusian theories. The law of diminishing returns is the economists' edition of a much more general law that one can find, differently expressed, in many other natural and social sciences. Some systems engineers will say that a system tends to an equilibrium, via the mechanism of negative feedback loops, which brings it to a stand still, or stationary situation. Physicists will speak of the law of entropy, as well as some economists 1 . How much of this theory, expressed at a high intellectual level, in different scientific branches, is really scientific and how much of it is of a cultural or ideological nature, is probably still open to discussion.

Nevertheless the fact remains that, coming back to economics, past growth has to be explained in spite - and within the framework - of the law of diminishing returns.

It is here that technology intervenes as the element, or as the coefficient, which

- by the introduction of an uninterrupted flow of new applied inventions - steadily 
pushes back the limits where one or the other of the production factors becomes rigid and unextendable.

In this sense, for instance, it is asserted that the malthusian theory has been defeated by the introduction of the potato. Adding up available land and known agricultural production on the one side, and the increasing populations on the other, Malthus came to the conclusion that these two trends were incompatible and that the world was condemned to starvation. At about the same time, the cultivation of the potato, coming from the new world, was introduced, which largely increased food production capacity.

Things then went even better, as we were really in the first phase of the first industrial revolution: the ancestor of the economic growth of modern times.

\section{Economic growth and technology during the first industrial revolution}

The first industrial revolution is associated with the spread of new technology: the flying shuttle loom and the steam engine are the main symbols of the first successful battle against the law of diminishing returns by the new industrial era.

This technology was in no way associated with science. It was the result of the improved knowledge of the engineer, based on practical experience and common sense. The steam engine was developed when science did not yet know what water was : the observation of how water is converted into steam by heating and the fact that the volume of the steam produced is much larger than the volume of the water is something anybody can easily make without any need for a laboratory. The same was true of the new looms : instead of using a hand to push the shuttle, why not just use a hammer, which struck the shuttle with the energy provided by the engine? The ability to develop this kind of technology is that of the engineer, or, more simply, of somebody possessing practical ingenuity and capable of making things work.

The basic technology of the first industrial revolution was the last step of the technology which man had been evolving since prehistoric times. The engineers of the stone age were those practical people who knew how to cut a stone, the same type of people who, in the iron age, knew how to smelt certain special types of earth to produce iron, without knowing scientifically what iron was in terms of chemistry and metallurgy.

This non-science-based-technology reached an unprecedented level of development in the course of the eighteenth century.

It was the core of the industrial revolution, which, by fits and starts spread from England to the Continent. It was only after 1850 that this economic growth movement started developing more or less simultaneously in different western countries.

From 1850 to 1873 , for example, rail mileage grew in Germany from 3,600 to 9,500 , in France from 1,800 to 11,500 , in Belgium from 500 to 2,300 and in the UK from 6,600 to 16,000 . Coal production followed the same trend in the four countries. The same, except for France, happened with raw cotton consumption.

In the course of these years, the first industrial revolution came to maturity, growth accelerated and spread rapidly. 
Then in the following years and in particular from 1873 to 1896 , prices fell to the extent of representing the most important deflation in the history of man.

In fact, deflation was a common phenomenon for most of the nineteenth century. From 1817, right after the Napoleonic wars, up to 1896, deflation was dominant with the exception of the period between 1850 to 1857 .

Economic theory, conditionning action, must share some responsibility for this. The stress was put on the supply side of the market : accepted economic laws stated that by definition all goods produced could be sold automatically. To stimulate demand directly was unacceptable. Many years had still to pass until the pressure provided by the economic crisis in 1929 on the one hand, and Keynesian theory on the other, led to action on the demand side of the market.

This was all the more necessary because the second industrial revolution was being prepared, providing a larger and larger reservoir of production capacity, as a result of the breakthrough of a new type of technology: science-based technology. Later on, the second world war provided a tremendous stimulus to bring this process to full maturity. The frontiers of diminishing returns were pushed so far back that they started to look really academic.

\section{Technology In the second Industrial revolution}

At the end of last century, scientific advances started to combine with technological advances. To quote Prof. Landes ${ }^{2}$ :

"Behind this kaleidoscope of change - sometimes marked by brilliant bursts, sometimes tedious in its complex fragmentation, always bewildering in its variety one general trend is manifest: the ever-closer marriage of science and technology. We have already observed the essential independence of these two activities during the industrial revolution; and noted that such stimulus and inspiration as did cross the gap went from technology towards science rather than the other way. Beginning in the middle of the nineteenth century, however, a close alliance develops; and if technology continued to pose fruitful problems for scientific research, the autonomous flow of scientific discovery fed a widening stream of new techniques."

This marriage was not fully realised by those personally involved. There are plenty of stories of scientists who were unaware of the practical applications of their discoveries, such as Alexander Bell.

But the most important thing to note is that, for instance, as a result of discovering what a molecule is and learning how to guild macromolecules, it became possible to produce new fibers. These transformations needed a laboratory and a knowledge of the subject which could not be acquired during normal day-to-day experience without specific mental and physical instruments, provided by the development of science. Physics, biology, chemistry, metallurgy and all the other sciences opened man's eyes so that he could see what bacteria were or detect invisible waves; in this way he could control the first (with enormous demographic consequences) and use the second to transmit sounds, light, images and heat. 


\section{The new production function}

Economics has grasped the new science-based technological phenomenon for what it apparently was in economic terms : a coefficient which was deepening and enlarging the production capacity of the major production factors, i.e. Capital and Labour. There has been a great deal of argument as to whether the impact of the technological coefficient has been greater in the case of Labour than of Capital.

In any case, evidence has been given of the close correlation between investment in research and development and economic growth, for the most significant periods of this development.

A statistical analysis conducted by Prof. Freeman of Sussex University for the period between 1935 and 1958 in the United States and the U.K., concerning 17 industrial sectors, provides clear evidence: the greater the technological effort, the higher the growth. For instance, in the United States, during the period 1935-58, the aeronautical sector invested in the research almost $40 \%$ of its total turnover and the industry grew by more than $6000 \%$. The corresponding figures for the electronics industry are : $25 \%$ of turnover invested for a growth of $1000 \%$; for the chemical industry : $8 \%$ of turnover for a growth of about $400 \%$; for the textile industry : $0,2 \%$ of turnover for a growth of $60 \%$.

It is worth nothing that technology, during the first industrial revolution, cost nothing. It was natural, therefore, to treat it as a coefficient.

It now seems that it would be more appropriate to build the production function, as some economists have suggested, including technology - or R \& $D$ investment as a production factor in its own right. The main reason for this is that $R \& D$ is something very different from the utilisation of Labour and Capital for a given output on a time basis. The cost of the $R \& D$ used and incorporated in a given output has been borne over a considerable amount of years before even the plants for the new products could be designed. $R$ \& $D$ operates in a totally dynamic reality with very long and varying lead times, coupled with a considerable uncertainty as to the results of each specific research project.

One needs to look at this problem closer.

\section{The dynamic nature of science-based technology}

Certainly the technological performance, in this century, has been bewildering. But the widely diffused images of "future shocks" implying continuous and accelerated change due to scientific innovations, are often misleading.

The big confusion starts at the point where the acceleration of the number of new products and services put on the market is taken as proof that technology can change things quicker and quicker. In the majority of cases, this is utterly false and it reflects the fact that, as Tolstoi said, changes are perceived when they have already taken place and not when they are under way.

The more a new technology is science-based, the more time is necessary to develop it. Physicists confirm that today any new fundamental discovery in physics will take 
at least 20 years to be applied. An even when a new technology has been developed in a laboratory to the level of a prototype, the industrialisation of thas process can take many years before it really "appears" to the public.

Let us take as an example the new generation of textile looms (so-called shuttleless looms). In the case of one of the major and most successful types of this new technological generation, the first ideas and designs were developed over ten years, from 1930 to 1940 , the first prototypes being developed from 1946 to 1960 . The first sales started in 1960 and it then took 15 years for these machines to achieve $10 \%$ of the total world market. What some traditional textile industries might still consider a " new technology", was already designed 40 years ago.

The public in reality has been struck by changes which are "sudden" because of psycho-sociological and social mechanisms : on the contrary, at the technical level, new changes are much more difficult and time-consuming today than they were in the last century.

What is often presented as an acceleration is often simply a reduction in the time needed for an industrialist to grasp the business opportunity offered by an available technology. In this way, photography took 112 years to be applied and transistors five. One must also take into account the existence of contradictory criteria used in order to determine which is the real discovery moment and which the moment of application.

In any case, the "accelerating pace of technology" is more a social problem than a technological reality.

On the contrary, the difficulty of setting up an $R$ \& $D$ policy and of estimating the economic relevance of the research is increased by lengthening lead times. The complexity and multidisciplinarity of research introduce a further element of delay.

Let not forget that the first landing on the moon was done on the basis of technology available ten years before, at the moment when the American space programme was prepared and approved.

\section{The limits of science-based technology}

The idea that technology has unlimited beneficial effects and potentials has been often directly or implicitly admitted, particularly during the sixties.

We can now list a series of considerations which show how technology is itself subject to the law of diminishing returns and in some cases even negative returns.

a) The first limitation come from the fact that technological lead times do not fit easily into the supply-demand equilibrium. Economic theory says that when a product is in short supply, its price will increase in such a way as to discourage demand and/or stimulate the supply of a competitive substitute. It would appear, then, that this mechanism stimulates new technologies because it stimulates substitution.

But this equilibrium is conceived as essentially static: in practical situations it means that it is short term. Most economic theory is based on static assumptions, where there is no room for dynamic factors. This was reasonable in more static situations than those prevailing after the second industrial revolution. 
Where substitution is subject to long delays, the supply-demand mechanism can even work the opposite way. Let us take the recent case of the energy crisis : the market price of oil reacted at first as if supply were inelastic. In reality, this inelasticity because of technology, is a factor of time : in fact we have an elastic supply situation, with a prolonged response delay. But because the market reacts in the short term, technological adaptability looks more and more as economic rigidity.

One could say that science-based technology introduces therefore, because of the delay bias, an element of economic vulnerability, in the sense that market supply/demand mechanism can fall - in the absence of external intervention and under given circumstances - into a self unfulfulling logic. The key problem is therefore to include in the supply/demand equilibrium these dynamic, delayed factors. This difficulty is aggravated in cases where concentration and markets have gigantic dimensions, as with fertilizers. We have here a world market of over 100 million tons : a variation in supply or demand of less than 1 percent (which can be due just to delays in shipping or to a couple of weeks of exceptional rain in an important agricultural zone) involves already a considerable volume of product, and as such can completely disrupt the price equilibrium, which can easily double or halve for very marginal quantities. Here again, disrupted prices for marginal quantities can disrupt investment (justified on longer-term considerations) far more than is warranted by the quantities involved on the price upheaval.

Let us now look at the cycles of technological innovation itself.

b) Technological change gives evidence of a series of superposed medium, long and very long-term cycles. Let us take the case of man-made fibers.

In the course of this century, we have experienced roughly two large invention cycles linked to two fundamental ideas. First, the birth, growth and development of the so-called artificial fibers, was based on the following idea : a natural fiber such as cotton is constituted of some sort of cellulosic material. Why not transform other sources of cellulosic material, with appropriate chemical treatments, in order to obtain other textile fibers? This basic idea opened up opportunities of finding various solutions. Three of four of the best of those solutions succeeded each other, and were the key element in the development of this industry. At the end of the whole cycle, everything suggested that further development could not be achieved through a new type of artificial fiber. The new development had to be sought in a new basic principle, answering the following new question : why use cellulosic material and why not just use whatever other chemical structure we can build provided it can be based on macromolecules and have appropriate properties? We can observe here that we have to do with more sophisticated scientific knowledge, and that the raw material is no longer similar to a natural fiber (cellulose being related to cotton), but is a very different source (oil) which has to be chemically rebuilt and transformed. And so, the synthetic fibers came into being.

Here again we can observe subsequent cycles of four major families (although the trade names give the impression that there are thousands), each of them giving a formidable propulsion to industrial development.

This second major cycle come to maturity in the last decade : new families of fibers have been invented but their application is more and more marginal, and 
compared with the past successes of the big four, rather insignificant. The bulk of research has been more and more concentrated for the last ten years on the improvement of existing fibers.

We are clearly here in a situation of diminishing technological returns.

The question would seem to be : how can a new fundamental cycle be initiated ? One answer has been research into non-wovens, but it has clearly failed. And it seems difficult to use the deepening knowledge of physics and chemistry to produce a revolutionary new approach, at least for the next decade. Of course one can argue optimistically and say : you can never predict fundamental changes, although this does not modify the time-lag problem. Or one can argue more pessimistically : we are more and more coming to the point were science-based technology, at least in certain sectors, has exploited all the major possibilities made available by the scientific advances of the last century.

Analogies with the fiber development cycles are easy to identify in other industrial sectors, such as aviation for instance, and many chemical products.

At this stage, some good opportunities appear still to exist in the electronics communication field and, of course, but with a rather long time lag, in the energy field.

Very extensive research into the present situation regarding time lags and cycles over the whole spectrum of technologies in all sectors is necessary. Our point here is that technological production is not immune from its own law of diminishing returns, which is implicit in the whole history of discovery and invention.

But that are other ways in which technology, by its very development, can have the effect of diminishing economic returns.

c) At the micro-economic level, the phenomenon of the diminishing returns of technology has been experienced in some industries for more than a decade already, at the level of the company body responsible for $R \& D$ investment.

The following graph gives an idea of the problem :

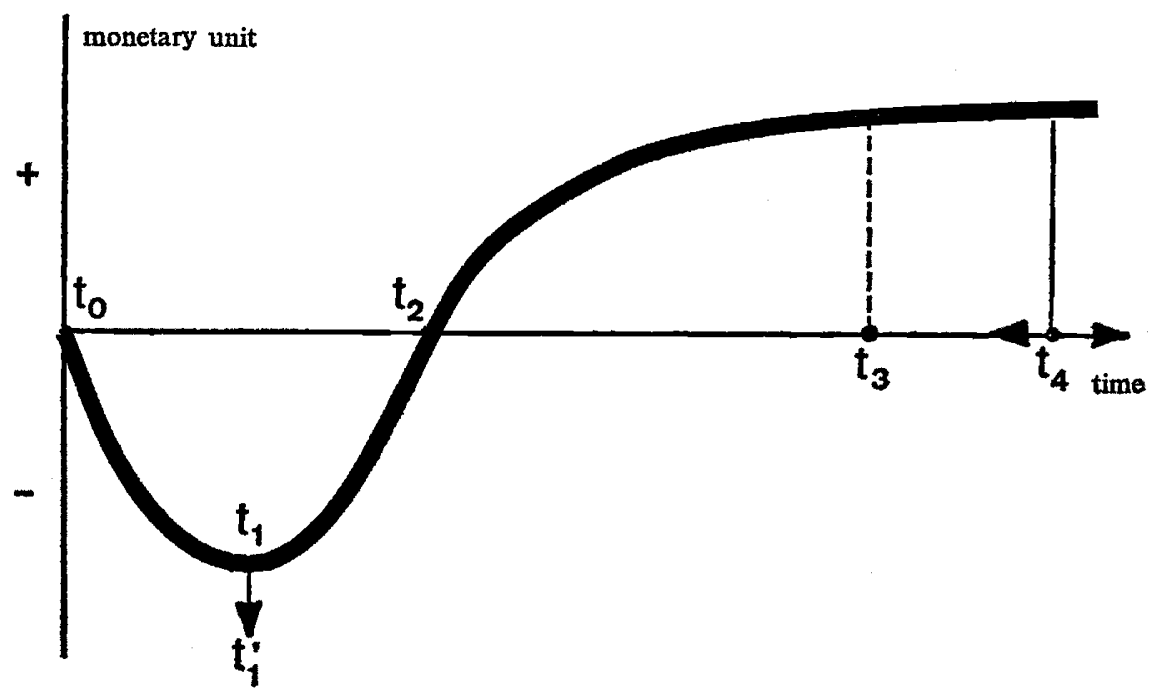


- at time $t_{0}$, a new research programme is started : money is invested with no possibility of any return until $t_{1}$;

- at $t_{1}$, the new research programme has started to yield a new product which is put on the market, but research continues to improve it and expand its applications, so that for a period of time, income is less than outlays on continuing research and product penetration costs ;

- only at $t_{2}$ does income match outlays; this marks the start of the period during which one must recover the deficit accumulated from $t_{0}$ to $t_{2}$;

- this deficit is offset at point $t_{3}$;

- the whole operation starts yielding net profit only after $t_{3}$;

- at $t_{4}$ another product is put in the market, which makes the first one obsolete, and therefore its marketable period is over.

This outline, of course, is simplified, but it helps to bring out the impact of trends which in many cases make the whole situation very vulnerable :

- at $t_{0}$ of a research programme, it must be borne in mind that as a rule, only less than 10 percent of projects will be successful. If investing some 100 millions dollars per year in $R$ and $D$, a company knows that 90 millions will be simply wasted. The successful part of the programme must therefore cover this net loss. In some industries, the situation is aggravated by the fact that the percentage of successes is diminishing, so that to make the probability law of large numbers operate, research - and therefore investment in it - must expand. There is a tendency therefore to deepen point $t_{1}$ towards $t^{\prime}$;

- increased research costs mean that the period for recovering them must be longer or that the market must be larger: the whole programme becomes more and more risky ;

- on the other hand, increased research means reduced obsolescence for the product : substitution will be quicker and quicker. This does not happen because - as we have seen - results can be achieved quickly, but because parallel research in the whole industry will, as a consequence, lead to comparable solutions which will curtail the available time for exploiting the benefits of a research project. The drive for substitution, which in all sectors has increased the trends towards shorter obsolescence time - or put more simply - which has resulted in products with a shorter and shorter life (" use and throw away" products, from the handkerchief to the watch) has become in many sectors a nonsense even in purely economic terms, as for instance the story of textile disposables (non-woven products) has shown. These trends have not yet completely generalized within industry as a whole, but they exist in those sectors of industry which have achieved maturity, and where a qualitative technological leap is out of the question for the next decade at least.

d) Technology, in many cases, means to produce something better, faster and in larger quantities. There is a tremendous push towards specialisation. In fact, a machine very often produces more, quicker and better a more limited amount of products than the machine which it has replaced. These improvements are often at the expense of range and flexibility. A clear example is provided by the modern shuttle-less looms which have superseded the traditional loom. Each of the new methods offers an 
advantage in a more restricted application. Limits are reached when for instance a single machine is capable of producing 500,000 blankets per year very efficiently, provided they are all of the same type, from all the points of view : materials, color, size, textile structure, etc. In cases such as this, specialisation becomes an economic attraction from the point of view of production, but an economic nonsense from the point of view of distribution and utilisation of the products.

e) The more decisive limits are of another nature. The success of technology seems to lead, paradoxically in many cases, to a situation in which production becomes marginal to the economic process. Producing more specialized products faster, in larger quantities, has the effect of : increasing the amount and selectivity of materials used in the manufacturing process, increasing storage problems once the product is manufactured, increasing distribution networks and increasing all the financial problems that go with it. It is more and more frequent for manufactured goods to have a final production cost at the plant ranging from 10 to $20 \%$ of what they cost to the ultimate consumer. In more and more cases, production has become an appendix of the distribution system for a great many products of our everyday life. It is not that profits are gigantic, but simply that technology, by concentrating production, has increased the amount and cost of the operations which intervene before and after this phase. Although economists still speak of the tertiary sector (services) as separate from the secondary sector (industrial production), the most important development in the advanced industrial economies is not the growth of the sector nominally classified as tertiary. Far more significant is the "tertiarization" of the secondary and primary (agricultural) sectors.

All this means that a lot of mistakes can be made when one does a cost/benefit analysis of a new product, at the manufacturing level. Apparent gains at that level can be more than offset by the increased costs involved in the whole system of distribution. Considerations of this kind some years ago, for instance, prevented the chemical industry from stepping up the individual capacity of ammonia or ethylene production units.

f) Technology encounters some limits also in terms of the environmental equilibrium. Economists developed in the past the concept of external costs: when one is building a railroad, the land withdrawn from agriculture represents a cost in terms for instance of lost agricultural production. But, with traditional technology, the problem of external costs remained, in the main, limited.

With science-based technology, it is another matter, because science-based technological production changes the structure of materials and modifies the natural recycling patterns. The problem of course is aggravated, in a cumulative way, by the total increase in production.

The production process itself can be seen as a waste-producing process : raw materials are extracted and part of them is thrown away, right at the place of extraction; they are refined, and another part is thrown away there : they are then treated or transformed and more waste is produced; the final products induce more waste at the distribution level ; finally, the end product is consumed or used until it is thrown away. Technology, in many cases increases the life span of natural recycling: often the more a product has been transformed because of scientific knowledge, the 
longer the recycling period and the recycling costs. The treatment of uranium wastes takes this phenomenon to its most costly and dangerous limits.

g) All these phenomena should be better evaluated at the macro-economic level. In fact, national accounting is based on the idea that every economic activity which is paid for is an added value. But, too often, added value is equated with economic growth or is treated as an index of economic welfare (the growth of GNP). It would rather seem that one of the main features of advanced industrial economies is that economic activity is not equivalent to economic welfare. Many, and more and more of the values added, are in fact values which are deducted from economic welfare, because of the wealth substracting by-products of the advanced technological-economic system itself. This phenomenon goes beyond the simple phenomenon of the external costs (where the problem is simply to " internalize" them). Investing in the anti-pollution industry does not increase economic welfare by increasing the nominal national income, so that the national community does not appear to have more wealth to dispose of. Similarly, buying an electrical machine, at home, to destroy part of the amount of waste a family produces in one day, is not an increase in welfare; it is just catching up with an induced cost, a deducted value, which has produced this type of need by the very kind of development characteristic of advanced economies.

In other words, in discussing welfare and net economic added value to wealth, one should start by discriminating between real added values and those which, curiously, are called added, but represent in fact deducted values. This would bring about more realistic assessments of real available national wealth upon which to build, for instance, a social policy.

The question of deducted values also brings up the problem of distinguishing between one level, the standard of living, and another level - the one which is represented by the accumulated deducted value - which represents a level of survival in the sense that it results in economic activities, consuming energy which is used for the preservation of production system itself, rather than being used directly for the purpose for which the whole economic system exists : to produce real wealth for people.

All these points are not intended to prove that science and technology are condemned once and for all to the law of diminishing returns. They merely emphasise some experiences of this last decade, which would need to be verified by a thorough analysis of all industrial and technological sectors. Many sectorial improvements are possible, some through the synergism of one sector influencing the progress of the other, as for instance the case of synthetic fibers offering a major opportunity for technological innovation in the knitting machinery industry. But, we have also seen that the unique economic growth of this century has a very specific origin in the historical unique marriage between science and technology, on the one hand. On the other, there are obvious limitations, which are all the more serious because of the time mechanism involved, in the science-technology-production sequence.

It is also possible that the future battle against the law of diminishing returns will find another coefficient, or another way to combine or interpret the production function. For the time being, the advanced industrial countries are living in a period of increased vulnerability. Understanding these vulnerabilities, and finding a way to control and reduce them is becoming of greater and greater importance. 
The limits of growth, which have been made popular by the Club of Rome, and exploited politically after the Kippur war of 1973 , are fundamentally due to limits internal to the production mechanisms, rather than simply external limits.

\section{Vulnerability and risk control in the modern European economy}

We mean by vulnerability the situation of a system (be it an industry, a group or a national economy) in which survival is imperiled by some specific events, acts or failures to act. When such events, acts or failures occur, the system is destroyed or at least fundamentally modified.

Many of the limits we have described in previous paragraphs are indices of vulnerability. We can regard vulnerability as depending on two types of risks : the positive and the negative (or pure) ones. The first are due to human initiative (the entrepreneurial risks implicit in a voluntary action), the second depend on unforeseeable events (an accident, an earthquake). These two risks are in most cases linked : a company starts selling a new product and takes the risk of finding a responsive market, but the production plants of the same company can burn down and therefore make it impossible for the company to play its entrepreneurial role. The same applies to individuals : the great majority of people have to work in order to live and if possible prosper, but a personal accident can make this goal impossible to achieve.

We can note that the situation of mature growth described in the previous chapters is characterized by the increasing vulnerability of the economic system, which can be expressed by the following two phenomena :

a) both types of risks are of growing dimensions due on the one hand to direct technological effects (concentration of production, deepening of scientific technology) and on the other hand to the growth of interdependence which increases the number of factors involved in the functionning of a system and which can be exposed to a breakdown; and

b) both types of risks are more and more inter-related: the higher the vulnerability levels, the greater the need for coordinated management of the two aspects of risk.

Let us consider first the entrepreneurial risk aspects of vulnerability management. Starting from what is described in the previous paragraphs, this is the case for instance with an $R$ and $D$ policy - at the level of industrial companies as well as of national economies - based on a detailed knowledge of the prospects of further progress, considering on the one hand the lead times and on the other the economic contraints. It is probable that in many cases, technological progress would have to be directed towards greater efficiency, aiming at decreasing economic and social vulnerability, developing other production and distribution criteria than those which lead to so-called economies of scale and higher speeds or larger capacities.

It is necessary in this case to estimate what are the real added values, internalizing all external costs and separating the deducted values: this is what fundamentally is meant or aimed to in the case of what is called "technology assessment", "environmental policy", "qualitative growth", "long-term energy policy", etc. All these are 
isolated concepts, isolated policies, producing isolated and conflicting results : they are all parts of what could be a clearer, integrated economic vulnerability management policy.

In a comprehensive vulnerability concept and policy, not only are the so-called entrepreneurial risks taken into consideration, but also the "pure" ones and their interrelation with one another. Vulnerability in advanced economies today is not the consequence of an accident - fire or earthquake - happening in a given place, as could have been the case twenty centuries ago. But the effects of these accidents, given the degree of urban concentration, the concentration of production, the interdependence of the economic system, etc. (which are all major effects of the second industrial revolution), tend to reach more and more catastrophic levels, increasing the system's vulnerability. Health, pollution, transport, energy production, social security are some of the major sectors in which more and more vulnerability problems arise : all types of risks are here closely inter-related, and they represent cost elements (very often of the deducted values type) which deserve closer attention.

Another problem confronts economists facing the assessment of vulnerabilities, in particular with regard to "pure" risks, some of which are typical of the commitments of the insurance industry. They do not generally fit into the production function, just like the technological factor. In fact, they are also dynamic, as technology is, in the sense that the damages related to production are a probabilistic pattern projected into the future, instead of being projected into the past, as technology is. The sequence is something like this :

- first, there is a period of research ;

- then a product, based on this research, appears on the market and is submitted as such to the price mechanism;

- this product, or this process of production, might be the cause of damages to the environment, to people, to property, in part at least due to unknown effects and in part due to pure accidents. If an insurance system is organized, a premium is collected (which is a production cost) for damages which will happen in the future in unknown conditions or time. As in the case of research, we have an element of unpredictability, for something happening after, and not before, the product is at the production or marketing stage.

Here again, we find a dynamic situation, which does not fit into the static framework of the demand and supply curves: it has been easier for economics virtually to ignore this important part of the indirect future costs of economic activity. Insurance, for instance, is often treated as a simple transfer service, with no added-value (or rather deducted value). In this case, economics has deprived itself of the possibility of using a tool to evaluate the actual costs of production implicit in the vulnerability of the production process itself.

Let us give an example of what this means in practice.

Let us assume that $1 \%$ of a given production is statistically bound to be destroyed by accident (a store, a machine, a weaving loom, etc.). After the accident, the damage will be replaced and will constitute part of the total added-value: in other words, 101 looms will be produced in order to have 100 exempt from damage or destruction. Everything is computed as added value, without acknowledgement of the part of it 
which represents an additional cost in keeping the rest running. In a static situation, in an economy of limited vulnerability, this might be satisfactory in practice. But in an advanced industrial economy, the problem is that the cost of "pure" risks increases proportionately faster than the average economic growth trend (which is another facet of the problems described in the previous paragraphs): this growth happens in a dynamic context of lengthening time limits, as in the case, for instance, of the longterm negative effects of drugs on health and on the environment. It would seem useful therefore to single out this economic cost element, in order to better measure it, understand its impact, and finally develop a significant branch of Risk Economics within the framework of general Economics, and in the specific context of the present phase of economic development of the advanced industrial countries.

\section{Inflation and the diminishing returns of technology}

Another important element of economic vulnerability is the persistent difficulty in dealing with inflation: among other factors, we believe that the understanding of the process of diminishing returns of technology can bring some light, by focusing attention on the increasing rigidities of the supply side of the economic equilibrium.

Achieving an equilibrium between the demand for and supply of goods and services is what economics is all about. When this equilibrium is not achieved, inflation (or deflation) - as Keynes said - is nature's remedy.

Looking back again at the economic history of Europe in the last two centuries since the advent of the industrial revolution, we can recall that "nature's remedy" had to work most of the time. We have already noticed that during the last century - if we exclude periods of war - it was mainly deflation which characterised the economic scene. Classical economists and most entrepreneurs had failed to fully understand the impact of new technology, which was adding to the factors of production a great capacity for reducing or even reversing the law of diminishing returns. Economists of the period believed that everything actually produced would be automatically consumed : there was thus no need to encourage either supply or demand. We can take as examples Ricardo's theory by which all savings were automatically invested and Say's law according to which production would have always be met by an equal demand. The effect of these theoretical beliefs was that many discoveries and inventions (as for instance photography) had to wait for a long time before becoming a marketable product, and as such produce value added, for reasons which often were not primarily technological. On the demand side, only nature acted from time to time in a "Keynesian" fashion : twice in the course of the century an important arrival of gold boosted demand and reversed the deflationary trend. The result was better exploitation of the production potential augmented by available technology and the start of a new economic cycle and upward growth path. Even a little inflation occured, but was then absorbed in a few years.

The effect of technology during the last two centuries of the industrial revolution (traditional technology plus science-based technology from the beginning on this century), has been to continually increase the potentiality of the supply of output. It was the existence of this potentiality in the economy, not clearly understood, which 
allowed Keynesians theories and methods of managing the economy by stimulating demand, to work. This also explains why, during the 1930's, it was essential to convince the public to augment their consumption. The application of a short run economic theory, like the Keynesian theory, was sufficient to keep the production machine running. Thanks to technology, the economy had accumulated enormous potential or hidden capacities, and under these conditions, it was right, for Keynes to stress that economic equilibrium could be achieved with full employment and that this was one of the possible equilibrium states.

Jumping from the mid-1930's to the present, we again find the industrialized world in a period of great economic uncertainty. Let us look closer at how we arrived at the present situation. In 1945, no economist or politician would have believed a forecast predicting the average level of economic growth actually achieved by the industrialized countries to 1973. The forecast of such reality would have been labeled as "extravagant".

As we previously stated, for economists, technology was a factor outside their production functions and their models; they did not feel that it was their job to include it in their analysis as an "endogenous" factor. Scientists were in the majority too keen on maintaining their aurea and had problems in admitting that engineers could exploit their findings. Engineers were too busy in designing and building new production units and new production processes in the chemical, mechanical, electrical, electronic and transport sectors, to bother about what they considered the general verbalisation of economists or the abstract thinking of the scientists.

Politicians, after the second word war, had at least learned something from the mistakes made after the first world war and helped to remove all sorts of barriers. Finally, we should not forget that war technology had given the last push to new science-based technological products. So, it could be said that the long period of growth occurred in spite of, or maybe because of, generalized nonunderstanding. And this represented a period during which technology became more and more an essential factor of production. ${ }^{3}$

Up to the late 1960's the system worked: "Keynesianism ", although a short-run and demand-based theory found greater and greater acceptance and benefitted paradoxically from a long-term economic-technological cycle which increased output potential. In the economic circles, the only alternative school of thought to gain wide acceptance has been the monetarists', who insist on closer management of the monetary mass, and who therefore tend to be more cautious than the Keynesians in controlling demand. But both, in the end, concentrate on demand and on short-run problems, whereas the key questions which should be asked are the following ones: What is happening to the equilibrium between supply and demand on the supply side? Is technology still providing the same type of new potential production as it did 10 or 20 years ago?

In reading the economic press, both on the theoretical and the journalistic level, one has the feeling that technology is something unscrutable but definitely without limits. Belief in technology, following upon 25 years of experience during which almost every economist has come to think "don't bother about it, it works", has often substituted closer analysis. Doubts about it are equated to doubts against human creativity and ingenuity. In some articles in the American, British or French press one 
can even find astonishing remarks such as: "The recent crisis was so deep, that the recovery to the normal rate of growth will be the next major problem " 4 , or " managers in industry take less initiatives with new products: they have less entrepreneurial attitudes than 20 years ago" 5 . The assumption of the economic journalist in the last remark is that technology is exploitable now just as it was 20 years ago, and present shortcomings are thus attributable to the industrial manager. We may wonder how far unverified assumptions can become a matter of faith. What are the reactions of an industrial manager, say in the chemical industry, to such criticisms after having experienced 20 or 30 years ago the booms of the new synthetic fibers and knowing that in the next few years there will probably not be a new product capable of producing a similar expansionary effect on the fiber market as did the introduction of nylon, acrylics, or polyesters !

All this is reflected in a recent analysis 6 of investment trends after cyclical downturns in the American economy since 1950 that has shown that after each recovery, industrial investment grew at a lower rate than in the previous cycle. In the present state of economy recovery, uncertainty on this point is greater than ever.

All this coincides also with the opinion of some economists, that we are experiencing at present a cyclical long-run period of reduced returns on capital.

If all these trends have their common origin in the phenomenon of diminishing returns of technology, there is no reason for bitter pessimism but rather grounds for fighting against the fatalistic pessimism growing in Europe. If, on the one side, we admit the case for a reduced possibility of long-term, sustained economic growth, a better understanding of the reasons for this will allow us to take better actions and perhaps - why not - to prepare the ground for a new golden era, even if this one may be as distant as the end of the century.

A more dangerous deep-routed pessimism is that generated by economist proposing actions to return to "traditional growth" without really justifying the envisaged mechanism. These economists have already had to face the fact that pushing for "traditional growth" has resulted in too many stop and go economic policies which have only served to aggravate the confidence of those managing the economy. They are now trying to save the "good old myth"' by saying that the economy disposes of more and more unemployed capacities and that the key to all solutions is to fight against bottlenecks. They have not recognized the fact that average figures on underutilisation of capacities say very little : the chain of production has expanded so much and multiplied the steps from the raw material to the final product, that inertia is becoming greater and greater. On the other side, the so-called bottlenecks cannot be easily overcome : they often reflect the existence of an economic rigidity directly linked with the phenomena of the diminishing returns of technology. A bottleneck is easy to find at the level of imports of raw material sources of energy, where no technology to present has provided adequate substitutes. Many bottlenecks are detectable at the intermediate production and distribution levels, for very understandable and objective economic reasons and not just for the lack of good adaptive management. The adaptation of interdependent production capacities is less and less a linear problem, solvable by increasing demand in the short-term. We must again insist on the fact that the understanding of why things happen is the key to reasonable optimism and appropriate action. 
Coming back to our considerations of inflation, we would then define the present state of affairs as nature's remedy for the squeeze between demand pressures and supply limitations. Although this is largely due to diminishing returns of technology, we must also remember that this analysis only takes into consideration the economic factors involved, even though these are always substantially modified by other social, historical and local factors within a given objective framework.

\section{REFERENCES}

1. GEORGESCU-ROEGEN, Nicholas, The Entropy Law and the Economic Process, Harvard University Press, Cambridge, Massachusetts, 1971.

2. LANDES, David, Technological Change and Industrial Development in Western Europe from 1750 to the Present, Cambridge University Press, 1972.

3. See also "Introduction à l'Economie du Risque et de la Sécurité", in the Etudes et Dossiers Nr. 3 of the Geneva Association, 1976.

4. The Economist, April 12, 1975.

5. This attitude is underlaying many economic articles published in different magazines, as Fortune, Business Week, Journal de Genève, in the last two years.

6. Business Week, "Capital spending is making its slowest postwar comeback from recession", September 14, 1976, 64. 